\title{
O ESPECTRO DE MARIÁTEGUI: HISTÓRIA, PRESENTE E HORIZONTE
}

\author{
EL ESPECTRO DE MARIÁTEGUI: HISTORIA, PRESENTE Y HORIZONTE
}

\section{THE SPECTER OF MARIÁTEGUI: HISTORY, PRESENT AND HORIZON}

\author{
DOI: http://doi.org//10.9771/gmed.v13i3.47175
}

João Rafael Chió Serra Carvalho ${ }^{1}$

\begin{abstract}
Resumo: Mariátegui é um dos pais fundadores do marxismo latino-americano e seu trabalho e legado são a causa de disputas ideológicas entre diferentes correntes do marxismo, tanto no Peru quanto alhures. Compreender seu pensamento, bem como suas recepções ao longo do século XX é uma janela privilegiada para a compreensão do desenvolvimento das lutas populares e do processo de descolonização na América Latina. Portanto, estudaremos não apenas os fundamentos da produção teórica de Mariátegui, mas também as disputas sobre seu legado no Peru, acompanhando os desenvolvimentos do Pensamento de Gonzalo, bem como o renascimento das lutas populares peruanas no século XXI.
\end{abstract}

Palavras-chave: Mariátegui. América Latina. Marxismo.

Resumen: Mariátegui es uno de los padres fundadores del marxismo latinoamericano y su obra y legado son la causa de disputas ideológicas entre diferentes corrientes del marxismo, tanto en Perú como en otros lugares. Comprender su pensamiento, así como sus recepciones a lo largo del siglo 20 es una ventana privilegiada para comprender el desarrollo de las luchas populares y los procesos de descolonización en América Latina. Por lo tanto, estudiaremos no solo los fundamentos de la producción teórica de Mariátegui, sino también las disputas sobre su legado en Perú, siguiendo los desarrollos del Pensamiento de Gonzalo, así como el renacimiento de las luchas populares peruanas en el siglo 21.

Palabras clave: Mariátegui. América Latina. Marxismo.

Abstract: Mariátegui is one of the founding fathers of Latin American Marxism and his work and legacy are the cause of ideological disputes between different currents of Marxism, both in Peru and elsewhere. Understanding his thinking as well as his receptions throughout the 20th century is a privileged window for understanding the development of popular struggles and the decolonization process(es) in Latin America. Therefore, we will study not only the fundamentals of Mariátegui's theoretical production but also the disputes over his legacy in Peru, following the developments of Gonzalo's Thought as well as the revival of Peruvian popular struggles in the 21st century.

Keywords: Mariátegui. Latin America. Marxism.

\section{Introdução}

Um espectro assombra Nuestra America - o espectro de Mariátegui. Não há nenhuma compreensão possível do marxismo latino-americano que não passe pelo estudo das obras de Mariátegui e suas recepções plurais. O Amauta ${ }^{2}$, como foi chamado no Peru, foi disputado, tanto em vida como na morte, por diferentes escolas de pensamento e concepções do marxismo e estes são os sinais indeléveis de sua perenidade e influência. Dos cursos da Universidade Florestan Fernandes, que pertencem ao MST ${ }^{3}$, no interior do Brasil profundo, às áreas sob o controle dos (neo)Zapatistas em Chiapas, passando pela guerrilha maoísta do $\mathrm{PCP}^{4}$ no interior do Peru, Mariátegui é reivindicado como guia teórico das mais ilustres praxes 
revolucionárias que possuem como norte comum a superação da exploração do homem e a retirada da humanidade de sua pré-história.

\section{Aqueles que o influenciaram}

Como Marx disse"... não é a consciência dos homens que determina sua existência, mas sua existência social que determina sua consciência." (MARX, 1977, prefácio). Assim, para compreender as muitas influências conflitantes da obra de Mariátegui (QUIJANO apud MARIÁTEGUI, 2007) é preciso compreender o processo de seus anos de formação.

Mariátegui nasceu em Moquegua em 14 de junho de 1894. Ele era um de três irmãos de uma família de origem pobre. Depois que seu pai abandona sua família, ele se muda com sua mãe e irmãos para Lima e, em seguida, para Huacho. Ainda durante a infância, sofreria uma lesão na perna e é internado em Lima por 4 anos, o que levou à sua longa anquilose e o fez parar de frequentar a escola. Mariátegui torna-se um leitor compulsivo, principalmente de obras religiosas, e aprende francês de forma autodidata durante seu longo período de internação.

Aos 14 anos ele começa a trabalhar no Jornal La Prensa e logo depois no El Tiempo. À época, ele também escrevia para as revistas Mundo Limeño, El Turf, Lulu e Colónida. (PORTOCARRERO,1994). Em 1918 cofundou com Cesar Falcon e Félix del Valle o jornal Nuestra Época. Em 1919, novamente com Falcão ele fundou La Razón onde endossaria a Reforma Universitária ${ }^{5}$ e inscreveria seu nome no movimento de luta dos trabalhadores peruanos.

Em outubro de 1919 ele é forçado a partir para a Europa pelo Governo Leguía. Ao lado de César Fálcon (Nuestra Época, La Razón) ele parte para a Europa sob uma falsa bolsa de estudos concedida pelo Governo a fim de escapar da prisão.

Em seu caminho para a Europa, ele foi passou pelos EUA onde testemunhou a enorme greve de trabalhadores das docas em sua chegada a Nova York. Também seria testemunha ocular da Revolta Spartacista ao chegar à Alemanha. ${ }^{6}$

$\mathrm{Na}$ Europa, estudou várias línguas e entrou em contato com artistas, intelectuais e militantes frequentando Conferências e Reuniões, tanto de movimentos acadêmicos quanto sociais. Finalmente, ele se radica na Itália, onde se casa com Anna Chiappe, com quem teria mais 3 filhos. Esteve presente na ocupação de fábricas em Turim e também ao XVI ${ }^{\circ}$ Congresso Nacional do Partido Socialista Italiano. ${ }^{7}$

Ele fazia parte dos círculos de estudo do $\mathrm{PSI}^{8}$ e fora durante este período que assumiu o marxismo como seu método. Depois de deixar a Itália, ele visitou Paris, Munique, Viena, Budapeste, Praga e Berlim, onde estudou os muitos movimentos revolucionários europeus do pós-guerra.

Em 17 de março de 1923, Mariátegui retorna a Lima. Em 1925 cofundou com seu irmão a Editorial Minerva, onde publica seu primeiro livro, uma antologia de ensaios chamada La Escena Contemporánea. Em 1926 fundou a El Amanta ${ }^{9}$, que provocou uma nova onda do Movimento Indigenista de Artes, Política e Literatura ${ }^{10}$; concomitantemente, também era colaborador nas revistas Variedades e Mundial.

Em 1927, Mariátegui foi preso sob acusação de conspiração e lhe foi concedida prisão domiciliar. Em 1928, ele se afasta de Haya de La Torre (APRA) ${ }^{11}$ e funda o PSP- Partido Socialista Peruano. Ele também funda a revista comunista Labor e publicou seu famoso Siete Ensaios.

Em 1929 fundou a CGTP - Confederação Geral dos Trabalhadores do Peru. ${ }^{12}$ Durante esse ano, ele enviou mensageiros para participar do Congreso Sindical Latinoamericano de Montevidéu ${ }^{13}$ e da 
Conferencia Comunista Latinoamericana ${ }^{14}$ (Argentina), onde seus escritos abririam uma dura controvérsia com as visões da Internacional Comunista para a América Latina

No final de março de 1930, ele fora internado devido a complicações de suas antigas lesões na perna. O Amauta morre aos 16 de abril, na véspera de sua viagem a Buenos Aires, onde trataria suas feridas e expandiria a revista El Amauta para toda a América Latina. Logo após sua morte, o PSP muda seu nome para PCP - Partido Comunista Peruano.

As influências de Mariátegui são um retrato composto de sua vida, sofrimentos, andanças e lutas. Mariátegui sempre permaneceu muito fiel à sua herança peruana e compreendeu seu povo de uma perspectiva de massa, a perspectiva daqueles que herdaram o Tahuantinsuyu ${ }^{15}$, assim as primeiras gerações de historiadores que escreveram sobre o Império Inca de uma perspectiva não paternalista podem ser encontradas ao longo de suas obras, homens como Von Hanstein, Ernesto Quesada, Thomas Joyce e Válcarcel. $^{16}$

Como intelectual, Mariátegui estava muito familiarizado com as discussões realizadas no Peru pósguerra $^{17}$ entre as elites liberal e conservadora. Além disso, sua educação piedosa o dotou de um profundo idealismo mítico que pode ser traçado nas influências de Miguel de Unamuno ${ }^{18}$, Bergson ${ }^{19}$ e Georges Sorel $^{20}$ que permeiam sua obra.

A partir do contato com a realidade estrangeira, Mariátegui adotará o marxismo como seu método. Um processo de aproximação do socialismo, que já havia começado como um flerte durante sua radicalização anos antes de seu exílio, à época ainda muito próximo de ideias anarquistas que permearam todos os círculos de radicalização dos trabalhadores na América do Sul na década de 1910. Será a partir de seus anos europeus em diante que podemos perceber claramente as influências de Marx, Engels e Lênin em seus ensaios políticos.

Sua estadia na Itália também afetaria profundamente seu pensamento. A partir desse momento, podemos encontrar influências que permaneceriam até sua morte, como a batalha de ideias entre os representantes do neohegelianismo ${ }^{21}$ radical e do neohegelianismo liberal ${ }^{22}$, bem como a abordagem de esquerda de Antônio Gramsci e o círculo intelectual do L'Ordine Nuovo. ${ }^{23}$ Uma última influência digna de menção de seu período europeu é a de Friedrich Nietzsche, de quem Mariátegui absorveu a ideia de uma necessidade radical de construir um novo homem, porém sob a égide de um pensamento emancipatório de toda a humanidade.

\section{Pensamento de Mariátegui: uma abordagem indígena multifacetada do marxismo na América}

\section{Latina}

Apenas duas das obras de Mariátegui foram publicadas durante sua vida, La Escena Contemporánea e Siete Ensayos de interpretación de la Realidad Peruana. ${ }^{24}$ Seus muitos ensaios, conferências, artigos, livros inacabados e uma peça curta foram publicados em sua maioria post mortem por sua família e herdeiros.

Um acervo de 20 volumes foi publicado após a morte do autor sob o nome biblioteca Amauta, dos quais 16 volumes foram escritos diretamente por Mariátegui e os outros 4 são biografias e antologias inspiradas em sua obra.

Estes 16 volumes compreendem principalmente sua produção entre 1923-1930. Suas obras juvenis, produzidas antes de seu exílio foram ostracizadas pelo próprio autor. A recuperação dessas obras começou no Peru a partir da década de 1970.

Entre os trabalhos mais importantes para conhecer a contribuição de Mariátegui para o marxismo na América Latina estão Ideologia y Política, Peruanicemos al Perú, Temas de Educacíon, Temas de Nuestra 

América e Punto de Vista antimperialistaI ${ }^{25}$, bem como os documentos da organização do Partido Socialista Peruano reproduzido por Martínez de la Torre em Apuntes para una interpretación marxista de la bistória del Perú (MARTÍNEZ DE LA TORRE, MARTÍNEZ DE LA TORRE, 1947).

Mariátegui escreveu, durante sua última década, sobre uma variedade colossal de temas como história, política, educação, questão indígena, religião, sociedade, raça, gênero, cultura, literatura, relações exteriores, mitologia, entre muitos outros. Devido ao escopo deste texto, optamos por apresentar suas ideias sobre a história da evolução da economia política peruana e suas relações com a questão indígena, uma de suas contribuições mais perenes para a teoria marxista.

Ao construir sua interpretação nativa da realidade peruana do ponto de vista marxista, Mariátegui achou cada vez mais necessário compreender o desenvolvimento histórico do empreendimento capitalista em Nuestra América considerando sua razão particular nas colônias que era avançar novos meios de produção sobre as bases dos pré-existentes. Isso levou Mariátegui a investigar a semifeudalidade ${ }^{26}$ do desenvolvimento capitalista no Peru, a qual ele explicou por meio do conceito de nove fases da economia peruana a partir de sua independência.

Primeiro houve o surgimento da indústria moderna: principalmente no litoral, o que levou ao nascimento de um proletariado industrial com crescente consciência de classe que mudou o cenário político.

A segunda fase é a do capital financeiro. A burguesia local tende a se tornar cada vez mais subserviente ao capital estrangeiro constituído principalmente por agências de bancos internacionais a princípio de origem britânica que invadiram e conquistaram o sistema econômico peruano.

Após esse período, houve a construção do Canal do Panamá que estimulou uma melhoria da posição geográfica do Peru. Em quarto lugar está a substituição da Inglaterra pelos Estados Unidos como principal parceiro financeiro do Peru. O Canal do Panamá desempenhou um papel importante, bem como a participação da firma North American nas indústrias de cobre e petróleo.

Essa conjuntura levou ao fortalecimento de uma classe capitalista menos ligada à classe proprietária de outrora. Os proprietários permaneceram poderosos, especialmente no campo, mas há um aumento mais proeminente de poder nas fileiras da burguesia

Logo após houve o breve período da ilusão de borracha. Um período de exploração agrária desse produto que terminou abruptamente e forçou o foco na reconstrução da economia de forma mais sólida devida à incapacidade da produção peruana competir com os novos avanços tecnológicos da indústria da borracha.

A reconstrução da economia nacional, direcionada ao mercado interno, levou ao período de subtilidade dos produtos europeus. Um boom de produtos peruanos cria um aumento nas fortunas domésticas. A hegemonia costeira da economia peruana aumenta em detrimento do campo e de seus proprietários, os gamonales $^{27}$ que ainda governam em base feudal sobre uma gigantesca massa de povos indígenas.

A substituição dos produtos estrangeiros foi rapidamente substituída pelo próprio capital estrangeiro. Assim, começou o período da política de empréstimos e endividamento. O restabelecimento do crédito peruano no exterior facilita os contratos públicos do Estado que são vitais para a economia. Esta nova onda de empréstimos veio principalmente da América do Norte.

Todos esses desenvolvimentos levaram à coexistência de três formas econômicas codependentes: o comunismo primitivo indígena na Serra ${ }^{28}$ ao lado de uma economia capitalista retardada na Costa que se desenvolveu a partir de um substrato feudal e de antigos proprietários, alguns persistindo no campo.

Apesar da crescente economia capitalista, o Peru permaneceu um país agrícola. Sua população indígena, quase $80 \%$ do total, continuou sendo principalmente rural. Sua produção mineral e agrícola era quase inteiramente exportada sendo responsáveis em conjunto pela manutenção dos empregos e da receita bruta do país. 
A elite de proprietários ainda estava organizada de forma pré-capitalista. Os outros setores da economia estavam, em sua maioria, direta ou indiretamente, nas mãos de capitais estrangeiros. Essa organização feudal dificultava o crescimento econômico do país.

Isso leva à ausência de desenvolvimento nas cidades litorâneas, com exceção de Lima, enchendo o campo com pequenos municípios e vilas contra uma enorme megalópole. A natureza autossuficiente, bem como a mentalidade de produzir para o exterior fazem da hacienda ${ }^{29}$ um mundo a parte.

O sistema de $\operatorname{tambos}^{30}$ subdesenvolve ainda mais o crescimento de cidades e haciendas, consistindo um sistema exploratório que ataca os campesinato. $O$ sistema administrativo opta por não regular as haciendas tornando-as uma concorrente injusta para o comércio de cidades pequenas.

O sistema de latifúndio é baseado em empréstimos externos e uma fome interminável por mais braços e terras. Uma vez que esses empréstimos não podem ser pagos, a terra em si é transmitida para empresas estrangeiras que arruínam ainda mais a economia doméstica.

O sistema de latifúndio serviu de base para a implantação de uma economia capitalista moderna e sucumbe à sua própria criação. Terratenentes tendem a se tornar intermediários do capital estrangeiro proprietário de terras. O maior perdedor nesta equação é, como sempre, a população indígena.

As raízes socioeconômicas desse problema podem ser encontradas na distribuição da terra ou, mais agudamente, na falta desta. O feudalismo em sua forma peruana, o gamonalismo, é o principal responsável por essa situação. O ataque contínuo do sistema colonial contra as formas de distribuição de terras e riquezas do Tahuantinsuyu levou a um sistema pós-colonial baseado na concentração de terras e recursos.

As pseudotentativas de abordar essa questão via regulação falharam em adquirir existência material fora da letra fria da lei. Os gamonales mantiveram seus poderes locais e não havia sistema administrativo capaz de retê-los. Portanto, a práxis era mais importante do que a lei escrita e, embora o sistema parecesse ter mudado em favor dos povos indígenas, a realidade permaneceu a mesma.

Nesse sentido, o período republicano foi, na maioria das vezes, ainda mais atroz contra as populações indígenas do que o próprio período colonial. A liderança do empreendimento colonial, muitas vezes baseada na tradição e religião em vez de resultados econômicos, tendia a ser mais tolerante com a população local do que os capitalistas ou os gamonales sob o regime capitalista híbrido que fora sendo implementado.

Assim, Mariátegui percebe esse período como o da modernização do Peru e aquele que faz da teoria marxista, seu método, o único capaz de compreender a realidade peruana se submetido às leis locais de desenvolvimento. Enquanto a administração colonial sustentava um sistema social baseado na religião, moralidade e tradição; sob o signo da República e, portanto, do empreendimento capitalista, os cortes de raça e classe surgiram como centrais para entender como a mercadoria enquanto forma sobredeterminava todas as outras formas de sociedade.

Esses avanços teóricos permitem que Mariátegui conclua que o problema dos povos indígenas no Peru é o problema da terra, uma conclusão que aproxima o pensamento de Mariátegui ao de Mao Zedong e que seria ainda mais enfatizada pelo Pensamento Gonzalo. ${ }^{31}$

A brutalidade do empreendimento colonial, a divisão racial e de classe que levou à exploração de corpos, culturas e geografias, as características da própria revolução criolla (onde sua superfície liberal escondia uma realidade ainda pior), tudo isso flui até a conclusão de que o Socialismo era a única solução, que só poderia vir de uma revolução cujo protagonistas fossem os próprios povos indígenas, para finalmente assim resolver a questão nacional. 
O legado de Mariátegui é tão diverso quanto seus próprios escritos. As muitas apropriações diferentes de seu pensamento devem nos mostrar que o Amauta era um pensador notavelmente complexo. A partir de sua morte, a disputa sobre seus ensinamentos (QUIJANO, 2007a; ARICÓ, 1978; IBARRA,2010; RUBBO, 2020) e sua linha de pensamento ocorreram no Peru e em toda a América Latina.

Um dos muitos campos em que o trabalho pioneiro de Mariátegui foi extremamente importante foi a compreensão da chamada Questão Nacional (FONTES, 2020). Autores como Mariátegui, Caio Prado Jr, Aníbal Ponce e sua geração tiveram que construir a teoria autóctone do zero usando como ferramenta a metodologia do pensamento marxista e sua práxis política.

Foi após a análise detalhada de Mariátegui sobre o desenvolvimento econômico social (sub)desenvolvimento de sua nação - que muitas gerações de marxistas latino-americanos foram capazes de entender ainda melhor suas superestruturas nacionais invertidas, consequência direta de uma cultura colonizada construída sobre uma economia estruturada para servir ao exterior por elites autofágicas e colonizadas (QUIJANO, 2007b).

Mariátegui foi um dos primeiros pensadores marxistas a apontar a necessidade de um processo de independência renovado através da revolução na América do Sul. Ele entendeu que as independências latino-americanas do século XIX, conduzidas de cima, não eram suficientes para promover países verdadeiramente independentes. Essa teoria da independência e da revolução influenciou pensadores marxistas tão distantes como Aníbal Quijano, José Aricó, Abimael Guzman e Luís Carlos Prestes.

Outro campo latino-americano profundamente influenciado pelo pensamento de Mariátegui, embora não necessariamente de acordo com as concepções do Amauta é o campo da Teoria da Dependência Marxista. Os criadores, Ruy Mauro Marini, Theotônio dos Santos e Vânia Bambirra foram todos leitores e espalhadores de seu pensamento. Outros intelectuais que foram influenciados por ou estiveram em discussão com os dependentes como Agustín Cueva, Aníbal Quijano e Florestan Fernandes tinham as concepções mariáteguinas na mais alta conta. Os estudos de Mariátegui sobre a formação econômica da América Latina e de suas classes dominantes foram influentes na discussão econômica dos anos 60, 70 e 80 em todo o continente.

A contribuição de Mariátegui para o campo do marxismo indo-americano não tem preço. Ele foi o primeiro intelectual a reconhecer não só a necessidade de participação da população indígena latinoamericana no processo, mas, sobretudo, a imperiosa necessidade de sua agência na condução das revoluções locais. Essa visão em si é mais do que suficiente para inscrever o nome do Amauta no panteão dos maiores marxistas de todos os tempos.

Até hoje, os povos indígenas de todo o continente americano lutam por sua independência e, sobretudo, por sua sobrevivência. Os exemplos são incontáveis da Patagônia ao Canadá. A virada decolonial, cuja maior vitória é trazer à tona a necessidade de descolonizar o pensamento, a política, a questão de gênero e a cosmovisão são extremamente dependentes dessa "descoberta".

Para citar um dos muitos exemplos desse legado podemos falar sobre a luta atual dos Guaranis e Kaiowas $^{32}$ no Brasil (JOHNSON \& ADOUE, 2020) que estão recuperando seus antigos territórios e se organizando no que pode ser descrito como um caminho socialista prático.

Assim como Mariátegui viu nos elementos ayllus ${ }^{33}$ o socialismo prático dos Incas, também os Guaranis e Kaiowas perceberam seu Ñande Reko ${ }^{34}$ como uma forma autônoma e anticapitalista de (re)organizar a sociedade e as relações humanas dentro de uma cosmovisão que não é guiada por nossas percepções de trabalho e mercadoria. Nesse sentido, seu modo de ser é precisamente pelo que o Amauta lutou com sua concepção de marxismo indo-americano.

As obras de Mariátegui também são influentes sobre o feminismo marxista na América Latina, o estudo clássico de Catalina Adrianzen (ADRIANZEN, 2018), feito na década de 1970, usa a visão de 

Mariátegui sobre a situação social no Peru para atender às necessidades de organização do movimento feminista marxista.

Durante sua vida, Mariátegui deu protagonismo a várias escritoras nas páginas de sua Revista Amauta. As mulheres, que bravamente enfrentaram a sociedade limenha de outrora para publicar seus trabalhos foram exaltadas por Mariátegui em diferentes ocasiões (GUARDIA, 2020).

Crescendo em um ambiente muito piedoso e tendo sido hospitalizado durante a maior parte de sua infância, Mariátegui era uma pessoa profundamente mística que permaneceu em contato com sua espiritualidade mesmo depois de abraçar o marxismo como seu método ao longo da vida. Muitas proximidades entre Mariátegui e James Connolly (CONNOLLY, 2019) podem ser observadas na forma como percebem a metafísica como um caminho e uma ferramenta para alcançar a mudança social.

Compreender a importância da religião e da espiritualidade é uma das principais chaves para qualquer linha de massa que pretenda ser devidamente aplicada na América Latina. Nesse sentido, as obras de Mariátegui falam tanto para os corações dos indígenas como para o camponês pobre ou proletário citadino a quem a religião, a espiritualidade e a presença do metafísico são tão importantes quanto a política mundana.

Mariátegui desde o início de sua carreira de jornalista foi um crítico da cultura e da literatura. Nesse sentido, Mariátegui, influenciado por seu período italiano e pelas obras de autores marxistas como Gramsci, percebeu a literatura e a cultura como campo de batalha por ideias progressistas. Ao longo de sua vida, esta tem sido uma das principais bandeiras de Mariátegui e também um de seus mais profundos legados.

Os estudos de Mariátegui têm um profundo impacto na crítica literária na América Latina, como podemos ver nas obras de Michael Löwy. Na frente cultural, Mariátegui foi influenciado pelas ideias do comissário Anatoly Lunacharski e seus ensaios sobre a práxis artística e cultural influenciaram gerações de artistas peruanos e latino-americanos. (MELIS, 2020; LOWY 2020)

Finalmente, devemos abordar a influência do pensamento de Mariátegui sobre o Pensamiento Gonzalo e a guerrilha maoísta no Peru. A concepção de Mariátegui sobre a necessidade da revolução como o único meio de conquistar uma independência adequada, bem como sua concepção de um marxismo indoamericano a ser criado como um esforço heroico, ao lado de sua descoberta sobre a necessidade da terra e da questão camponesa para que esta revolução seja iniciada no campo, colocou o pensamento de Mariátegui em uma linha semelhante à do pensamento de Mao Zedong. ${ }^{35}$

É precisamente ao adaptar as visões mariáteguianas às do presidente Mao e adaptá-las criativamente à sua própria realidade que o PCP e seu presidente Abimael Guzman declararam a guerra popular prolongada como a única maneira possível de realizar a revolução no Peru. (KISTLER; HALLQVIST, 2016; BORJA, 1989)

\section{Perspectivas do pensamento marxista na América Latina}

O pensamento de Mariátegui permanece tão importante para a compreensão da realidade da América Latina como nos dias em que foi escrito. Um dos mais originais, complexos e profundos marxistas latino-americanos, a obra de Mariátegui ainda é uma fonte de descoberta e perplexidade. Mariátegui com as ferramentas de seu tempo avançou o pensamento marxista e adaptou-o à sua própria realidade, confiando no marxismo como um método de compreensão das totalidades de uma realidade em movimento e mudança, a fim de transformar essa mesma realidade profundamente.

Algumas das principais contribuições do Amauta foram compreender a necessidade da revolução como uma condição sine qua non para que a verdadeira independência desenvolvesse uma percepção do indigenismo como uma janela para compreender como raça e classe operam na América Latina; expondo 
em toda a sua brutalidade a verdadeira natureza da burguesia e das oligarquias locais; bem como apontando a importância do problema da terra e da consciência de classe do campesinato em Nuestra America.

Se o próprio Mariátegui muitas vezes apontou os apristas como o Kuomintang da América do Sul, devemos reconhecê-lo como nosso Mao Zedong. Mariátegui entendeu a alma do povo latino-americano e sua formação e procurou fornecer agência àqueles que eram invisíveis à sua sociedade.

Nesse sentido, podemos dizer que Mariátegui triunfou sobre o que ele mesmo disse que a construção do marxismo latino-americano deveria ser:

No queremos, ciertamente, que el socialismo sea en América calco y copia. Debe ser creación heroica. Tenemos que dar vida, con nuestra propia realidad, en nuestro propio lenguaje, al socialismo indo-americano. He aquí una misión digna de una generación nueva. (MARIÁTEGUI, 1972, p. 248-249) 36 $^{36}$

Se quisermos ser dignos de levar seu legado para o novo milênio, também devemos dar vida a um novo socialismo indo-americano e a uma nova geração de militantes e intelectuais comprometidos não apenas em descolonizar o pensamento, mas sobremaneira em revolucionar a política.

\section{Referências:}

ADRIANZEN, Catalina. Marxismo, Mariátegui e o Movimento Feminino. São Paulo: Nova Cultura, 2018.

ARICÓ, José. Mariátegui y los orígenes del marxismo latinoamericano. Ciudad de Mexico: Ediciones Pasado y presente, 1978

BIAGINI, Hugo. La Reforma Universitaria en Nuestra América. Buenos Aires: Editorial Octubre, 2018 .

BORJA, Luis Arce. Guerra Popular en el Peru - E1 Pensaiento Gonzalo. Bruxelas: El Diario, 1989.

CANSECO, María Rostworowski de Diez. Historia del Tahuantinsuyu. Lima: IEP, 2018.

CASTRO-GÓMEZ, Santiago. El giro decolonial: Reflexiones para una diversidad epistémica más allá del capitalismo global. Bogotá: Siglo del Hombre, 2007.

CONNOLY, James. Socialismo e Religião. São Paulo: Baioneta, 2019.

ESCORSIM, Leila. Mariátegui: Vida e Obra. São Paulo: Expressão Popular, 2006.

FONTES, Yuri Martins. Afinidades entre Mariátegui e Caio Prado: Questão Nacional, metodologia e práxis. Apud: RUBBO, Deni Alfaro; ADOUE, Silvia (orgs.) Espectros de Mariátegui na América Latina. Marília: Lutas Anticapital, 2020.

FUNES, Patricia. Salvar la nación: intelectuais, cultura y política en los años veinte latinoamericanos. Buenos Aires: Prometeo Libros, 2006.

GONZALES PRADA, Manuel. Horas de Lucha. Caracas: Biblioteca Ayacucho, 1976

GSCI (Secretaria Geral da Internacional Comunista), E1 Movimiento Revolucionário Latino Americano. Buenos Aires: Editorial Sudam, 1930.

GUARDIA, Sara Beatriz. Mariátegui, uma visão de gênero. Apud: RUBBO, Deni Alfaro; ADOUE, Silvia (orgs.) Espectros de Mariátegui na América Latina. Marília: Lutas Anticapital, 2020.

IBARRA, Eduardo. El pez fuera del agua: crítica al ultraizquierdismo gonzaliano. Lima: J. Gutemberg, 2010.

JOHNSON, Felipe; ADOUE, Silvia. Retomadas Guarani e Kaiowá: o socialismo indo-americano e a busca da Terra sem Mal. Apud: RUBBO, Deni Alfaro; ADOUE, Silvia (orgs.) Espectros de Mariátegui na América Latina. Marília: Lutas Anticapital, 2020. 
KAPSOLI, Wilfredo. Mariátegui y los congresos obreros. Lima: Amauta, 1980

KISTLER, Christophe; HALLQVIST, Josef. Obras recolhidas do Partido Comunista do Peru. Vol 1 1968-1987. Utrecht, 2016.

LANDER, Edgardo. La colonialidad del saber: eurocentrismo y ciencias sociales. Perspectivas latinoamericanas. Buenos Aires: CLACSO, 2000.

LÖWY, Michael. O marxismo na América Latina. Uma antologia de 1909 aos dias atuais. São Paulo: Expressão Popular, Ed. Perseu Abramo. S. P. 2016

LÖWY, Michael. José Carlos Mariátegui e a cultura revolucionária: do romantismo ao surrealismo. Apud: RUBBO, Deni Alfaro; ADOUE, Silvia (orgs.) Espectros de Mariátegui na América Latina. Marília: Lutas Anticapital, 2020.

MAGRI, Lucio. O alfaiate de Ulm. Nova Iorque: Verso, 2011.

MARIÁTEGUI, José Carlos. Defensa del marxismo. Lima: Empresa Amauta, 1978.

MARIÁTEGUI, José Carlos. Faça sonho às coisas. São Paulo: Boitempo, 2005a.

MARIÁTEGUI, José Carlos. Educação e América Latina. São Paulo: Nova Cultura, 2019

MARIÁTEGUI, José Carlos. Ideologia y política. Lima: Biblioteca Amauta, 1972

MARIÁTEGUI, José Carlos. Obras completas. Lima: Biblioteca Amauta.

MARIÁTEGUI, José Carlos. Mariátegui total. Ed. Amauta, 1994.

MARIÁTEGUI, José Carlos. Por um socialismo indo-americano. Rio de Janeiro: Ed. UFRJ, 2005b.

MARIÁTEGUI, José Carlos. Siete ensayos de interpretación de la realidad peruana. Caracas: Fundación Biblioteca Ayacucho, 2007.

MARTÍNEZ DE LA TORRE, Ricardo. Apuntes para una interpretación marxista de la Historia Social del Perú. Lima: Empresa Editora Peruana, 1947.

MARX, Karl. Contribuição para a Crítica da Economia Política. Moscou: Editores do Progresso, 1977

MELIS, Antônio. A luta de José Carlos Mariátegui na frente cultural. Apud: RUBBO, Deni Alfaro; ADOUE, Silvia (orgs.) Espectros de Mariátegui na América Latina. Marília: Lutas Anticapital, 2020.

MELO, Sydnei. Mito, Religião e Socialismo nos Escritos de José Carlos Mariátegui. Apud: RUBBO, Deni Alfaro; ADOUE, Silvia (orgs.) Espectros de Mariátegui na América Latina. Marilia: Lutas Anticapital, 2020.

MESSEGUER, Diego S. J. La ideia de revolución en el pensamiento de José Carlos Mariátegui. Tese de doutorado. Paris, 1974.

MURÚA, Martín de. Historia general del Perú: origen y descendencia de los incas. Introdução y notas Manuel Ballesteros Gaibrois. Madrid: Instituto Gonzalo Fernández de Oviedo, 1962-1964. 2 v.

PERICÁS, Luiz B. José Carlos Mariátegui e o Comintern. In: Lutas Sociais, n. 25/26, São Paulo, 2011.

PERICÁS, L.B. (org) José Carlos Mariátegui: Revolução russa, história, política e literatura. São Paulo: Expressão Popular, 2012

PERICÁS, L.B. Mariátegui sobre educação. São Paulo: Xamã, 2007.

PORTOCARRERO, Julio. Sindicalismo Peruano: primeira etapa, 1911-1930. Lima: Trabalho, 1987

PORTOCARRERO, Ricardo G. Crônica Bibliográfica: José Carlos Mariátegui y su edad de piedra (1930-1993) em: Revista Andina, ano12, n²3, Cusco, julho de 1994, pp.217-253

SULMONT, Denis. Historia del Movimiento Obrero en el Perú. Lima: TAREA - Centro de Publicaciones Educativas, 1977. 
QUIJANO, Aníbal. José Carlos Mariátegui: Reencuentro y debate. Apud MARIÁTEGUI, José Carlos. Siete ensayos de interpretación de la realidad peruana. Caracas: Fundación Biblioteca Ayacucho, 2007a.

QUIJANO, Aníbal. Treinta años después: otro reencuentro. Notas para otro debate. Apud MARIÁTEGUI, José Carlos. Siete ensayos de interpretación de la realidad peruana. Caracas: Fundación Biblioteca Ayacucho, 2007b.

RUBBO, Deni Alfaro. Difusão e circulação do marxismo na periferia: Mariátegui e a "teoria da dependência". Apud: RUBBO, Deni Alfaro; ADOUE, Silvia (orgs.) Espectros de Mariátegui na América Latina. Marília: Lutas Anticapital, 2020.

TAURO, Alberto. Amauta y su influencia. In: MARIÁTEGUI, José Carlos. Mariátegui Total. Ed. Amauta, 1994

\begin{abstract}
Notas
${ }^{1}$ Educador popular e historiador, mestre em História Social pela Universidade de São Paulo, doutorando em História Social da Cultura pela Universidade Federal de Minas Gerais (UFMG). Currículo Lattes: http://lattes.cnpq.br/6317606186300232; Orcid: https://orcid.org/0000-0001-5864-9046. E-mail: boldogor@gmail.com.

2 De acordo com Frei Martin de Murua, a educação do Império Inca fora organizada em escolas chamadas Yachaywasi, onde aos futuros governantes do império eram ensinados princípios governamentais, estatística, matemática, ciência, interpretação de khipus, história, agronomia, arquitetura, cosmologia dentre muitos outros assuntos. Esta educação constituía o saber de um amauta, uma mistura de sábio e professor, que transmitia esse conhecimento oralmente para as gerações futuras. Sobre o assunto, ver MURÚA, Martín de. Historia general del Perú: origen y descendencia de los incas. Introdução y notas Manuel Ballesteros Gaibrois. Madrid: Instituto Gonzalo Fernández de Oviedo, 1962-1964. 2 v.

3 MST, em Português Movimento dos Trabalhadores Rurais Sem Terra. O Movimento dos Trabalhadores Rurais Sem Terra é o maior movimento camponês do Brasil, composto atualmente por mais de 350 mil famílias espalhadas por 24 estados diferentes do Brasil. O movimento ao longo de seus 30 anos organizou escolas formativas e Universidades em seus acampamentos onde a obra de Mariátegui é um dos temas obrigatórios. Sobre o assunto ver MORISSAWA, Rio Mitsue. A História da Luta pela Terra e o MST. São Paulo: Expressão Popular, 2001.

4 O PCP, em espanhol, Partido Comunista del Peru (Partido Comunista Peruano) é um Partido Marxista-Leninista-Maoísta fundado na década de 60 por estudantes e professores da Universidade do Peru, principalmente os da província de Ayacucho. Seu fundador e líder, Abimael Guzman (Presidente Gonzalo), professor de filosofia da Universidade Nacional de San Cristóbal de Huamanga desenvolveu uma linha de pensamento única chamada Pensamiento Gonzalo que é uma interpretação sob a chave maoísta de muitas das ideias de Mariátegui readaptadas à realidade peruana dos anos 60, 70 e 80 . A guerrilha foi dissipada no início dos anos 90 e reapareceu na primeira década do século XXI. Sobre o assunto ver IBARRA, Eduardo. El pez fuera del agua: crítica al ultraizquierdismo gonzaliano. Lima: J. Gutemberg, 2010.

5 A reforma universitária de 1918 foi um movimento que começou na Argentina para democratizar o acesso à educação universitária e realizar uma modernização geral das Universidades. Os eventos, que começaram em Córdoba, acabaram se espalhando primeiro para toda a Argentina e depois para a maior parte da América Latina. Mariátegui esteve envolvido nos desdobramentos desses eventos ocorridos no Peru. Sobre a própria reforma ver BIAGINI, Hugo. La Reforma Universitaria en Nuestra América. Buenos Aires: Editorial Octubre, 2018

6 A Revolta Spartacista, liderada por Rosa Luxemburgo e Karl Liebnecht, foi uma tentativa de revolução na Alemanha do pósguerra evitada pela força bruta pelo governo social-democrata liderado por Ebert e seu grupo. Sobre o assunto ver HAFFNER, Sebastian. Fracasso de uma Revolução: Alemanha 1918-1919. Library Press, 1973.

7 Este Congresso foi o berço do PCI -Partido Comunista Italiano. Sobre o assunto ver MAGRI, Lucio. O Alfaiate de Ulm. São Paulo: Boitempo, 2015

8 Partito Socialista Italiano (Partido Socialista Italiano), o antecessor de PCI - Partito Comunista Italiano (Partido Comunista da Itália).

9 Ver nota 1. Esta revista entraria para a história como a contribuição mais proeminente para a cultura política peruana em todo o século XX. Sobre o impacto da revista ver TAURO, Alberto. Amauta y su influencia. In: MARIÁTEGUI, José Carlos. Mariátegui Total. Ed. Amauta, 1994.

10 A primeira onda da literatura indigenista peruana tinha acontecido na década de 1890, mas ainda era focada em um ponto de vista branco e eurocentrista. Tal literatura refere-se aos povos indígenas sempre em voz passiva, retratando-os como incapazes e ingênuos através dos olhos do progresso ou da piedade. Um dos melhores exemplos dessa literatura é o livro clássico de TURNER, Clorinda Matto de. Aves sin nido. Barcelona: Linkgua, 2014.

11 O Alianza Popular Revolucionária Americana (APRA - Aliança Popular) ou PAP - Partido Aprista Peruano foi um movimento nacionalista que pretendia criar uma aliança latino-americana mais ampla de movimentos sociais e políticos anti-imperialistas. Seu fundador, Víctor Raul Haya de la Torre tinha visões revolucionárias menos profundas do que as de Mariátegui, o que levou ambos à uma separação. O APRA era membro do internacional socialista, mas o próprio Mariátegui se referiu a ele como a versão latinoamericana do Kuomintang devido à sua visão socialista nacionalista democrática de centro-esquerda. Sobre a APRA recomendamos KANTOR, Harry. El Movimiento Aprista Peruano. Lima: Editorial Pleamar, 1964.
\end{abstract}


12 Até hoje o CGTP é o maior sindicato nacional peruano. Foi fundado por Mariátegui em 1929, colocado na ilegalidade em 1930 e brutalmente perseguido nas décadas seguintes. Seus líderes sofreram perseguição, prisão e exílio. Sobre as lutas do movimento operário no Peru ver SULMONT, Denis. Historia del Movimiento Obrero en el Perú. Lima: TAREA - Centro de Publicaciones Educativas, 1977.

13 O Congresso Sindical Latino-Americano de Montevidéu ocorreu em maio 1929 no Uruguai. Foi amplamente coberto pela Revista Amauta, principalmente em sua edição número 23. As delegações que participaram do Congresso representaram mais de 800.000 trabalhadores de pelo menos 11 países. Sobre o assunto ver Amauta, n²3, seções Movimiento Sindical e Panorama Móvil disponível em http://www.socialismo-chileno.org/PS/amauta/23.pdf, acessado em 17 de fevereiro, 2021.

14 Do primeiro ao décimo segundo dia de junho, a Conferência ocorreu em Buenos Aires com 38 delegados dos Partidos Comunistas da Argentina, Brasil, Bolívia, Colômbia, Cuba, Equador, El Salvador, Guatemala, México, Panamá, Paraguai, Peru, Uruguai e Venezuela. Os chilenos foram representados indiretamente devido ao terror branco no país. Além dos delegados dos partidos também havia representantes da Internacional Comunista, da Juventude da Internacional Comunista, do Partido Comunista dos EUA, do Partido Comunista da França e do secretariado da Juventude Comunista Sul-Americana. As atas das reuniões e dos debates podem ser encontradas em: GSCI (Secretaria Geral da Internacional Comunista), El Movimiento Revolucionário Latino Americano. Buenos Aires: Editorial Sudam, 1930. Para ver uma discussão sobre a participação de Mariátegui no Congresso recomendamos PERICÁS, Luiz B. José Carlos Mariátegui e o Comintern. Em: Lutas Sociais, n. 25/26, São Paulo, 2011.

15 Tahuantinsuyu ou tawantinsuyo é o nome do Império Inca em Quéchua. O nome deriva de Tawa (quatro) mais o infixo ntin (grupo) e suyo (região). O "grupo de quatro Regiões" refere-se às 4 subdivisões do Império Inca que foram unidas por sua capital, Cuzco. Sobre o assunto CANSECO, María Rostworowski de Diez. Historia del Tahuantinsuyu. Lima: IEP, 2018.

16 Otfried Von Hanstein publicou seu agora clássico El Mundo de los Incas: Un estado socialista del pasado em janeiro de 1924; Ernesto Quesada publicou seu El Problema del Idioma Nacional na virada do século em 1900; o antropólogo Britânico Thomas Athol Joyce escreveu o famoso South American Archeology em 1912 e Luis Eduardo Válcarcel Vizcarra, historiador, arqueólogo e famoso representante da corrente indigenista peruana escreveu seus três livros mais icônicos na segunda metade dos anos 20; Del Ayllu al Imperio (1925), De la vida incaica (1925) e Tempestad en los andes (1927), esta última sendo publicada pela Editorial Minerva, editora dos irmãos Mariátegui. Entre esses homens havia a visão comum do Império Inca como uma comunidade protosocialista.

17 Referimo-nos à Guerra do Pacífico, um conflito envolvendo Peru, Chile e Bolívia que durou de 1879 a 1884. O Peru foi o maior perdedor desta guerra e sua economia e sociedade sofreram profundamente os resultados do conflito. Ver SATER, William F. Andean Tragedy: Fighting the War of the Pacific. 1879-1884. Lincoln: Universidade de Nebraska Press, 2007.

18 Miguel de Unamuno (1864 - 1936) foi um escritor, ensaísta e filósofo espanhol. Suas obras derivam do racionalismo e positivismo e seu pensamento religioso foi principalmente inscrito na tradição do existencialismo cristão. Suas obras, tanto na filosofia como na literatura, foram profundamente influentes na cena intelectual peruana durante a vida de Mariátegui.

19 Henri Bergson (1859-1941) foi um escritor e filósofo francês, bem como o vencedor do Prêmio Nobel de 1927. Bergson era um representante da filosofia continental metafísica. Seu pensamento pode ser inscrito na tradição do espiritismo e do vitalismo. Ele foi um filósofo muito influente na França durante seus dias e a intelectualidade sul-americana tendia a acompanhar a agenda continental. Assim, a obra de Bergson foi muito influente no Peru de Mariátegui.

20 George Eugene Sorel (1847 -1922) foi um pensador social, teórico político e jornalista francês. Depois de um começo liberalconservador, Sorel evoluiu para uma perspectiva marxista e, em seguida, para uma social-democrata e sindicalista. Uma das principais influências sobre Mariátegui durante sua estadia na Europa, a concepção de Sorel de sindicalismo permaneceu importante para Mariátegui até sua morte.

21 Entendemos o neohegelianismo radical como a doutrina personificada em homens como Piero Gobetti. Um credo que, ao mesmo tempo, foi profundamente radical em seu objetivo de mudança política e ainda muito idealista em sua abordagem à mudança social. Revistas como La Rivoluzione Liberale e Il Baretti são exemplos perfeitos de tal idealismo. Apesar de seu credo marxista a estadia de Mariátegui na Itália foi profundamente influente em sua obra posterior e a batalha de ideias entre o neohegelianismo radical, o neohegelianismo liberal e a abordagem marxista italiana da sociedade e da cultura teriam um impacto profundo no trabalho do Amauta.

22 Entendemos o neohegelianismo liberal, especialmente na Itália, como a corrente que segue o pensamento idealista de Benedetto Croce e Giovanni Gentile cuja abordagem neo-idealista em relação à filosofia abre um caminho político para a extrema direita. Correntes como o neohegelianismo radical de Gentile e o pensamento marxista de Gramsci e do círculo do L'Ordine Nuovo iriam travar as lutas entre as ideias da esquerda e da direita.

23 A abordagem do marxismo de Gramsci e do L'Ordine Nuovo e o peso que eles colocam na mudança cultural através da organização política têm um impacto por todo o pensamento de Mariátegui. Toda a sua produção de crítica cultural a partir de seu período italiano em diante depende profundamente dessa abordagem.

24 Ambos foram publicados pela Editorial Minerva, editora que Mariátegui fundou ao lado de seu irmão. La Scena Contemporánea foi publicado pela primeira vez em 1925 e Siete Ensayos em 1928.

25 Os quatro primeiros livros, publicados na Biblioteca Amauta, são, na ordem em que aparecem no texto, os volumes 13, 11, 12 e 14. O último é um único texto apresentado antes de ambos os Congreso Sindical Latinoamericano de Montevidéu e à Conferencia Comunista Latinoamericana.

26 O conceito de semifeudalidade, muito controverso especialmente no campo marxista da América Latina, pode ser resumido na continuidade de modelo de produção pretérito durante a égide de um novo. Por exemplo, chamamos de semifeudalidade o fato de que muitos trabalhadores no Brasil hoje em dia ainda percebem seus salários em muitos latifúndios e plantações de forma précapitalista, como ser pago em gêneros, mercadorias ou crédito no armazém local. Sobre o desenvolvimento do conceito no pensamento de Mariátegui recomendamos o ensaio Esquema de la Evolución Económica, o primeiro dos "sete ensaios".

27 Gamonales é um termo peruano para se referir à classe terratenente que foi cunhado no século XIX a partir da palavra gamón, uma planta parasitária cujo crescimento acontece às custas das outras plantas ao seu redor. O gamonales eram proprietários cujas terras e poder cresceram a partir dos antecessores comunais indígenas, os ayllus, por sua vez um terreno comum usado pela comunidade para se manter. Gamonalismo foi um fenômeno típico peruano, mas as características da classe terratenente na 
América do Sul são comuns à maioria de seus países. Sobre o assunto um dos primeiros usos do termo pode ser encontrado em GONZALES PRADA, Manuel. Horas de Lucha. Caracas: Biblioteca Ayacucho, 1976.

28 A partir da época de Mariátegui muito tem sido pesquisado sobre a História do Tahuantinsuyu. Trabalhos contemporâneos mostraram que o sistema econômico do Império Inca era muito mais complexo do que a categoria de economia social primitiva (VON HANSTEIN, 1924) ou comunismo primitivo indígena (MARIÁTEGUI, 2007) nos levou a acreditar. No entanto, seu sistema econômico não se baseava na forma valor como passa a ser compreendia na crítica marxista à economia política.

29 A hacienda costeña (latinfundium costal) foi a principal forma de exploração terrestre no Peru desde a conquista espanhola. Sobre o assunto ver ARROYO, Eduardo. La Hacienda Costeña en Perú. Lima: Centro de Proyeccion Cristiana, 1981.

30 Um Tambo (Quéchua for Estalagem), foi uma estrutura inca construída ao lado de estradas a cada 20 ou $30 \mathrm{~km}$ durante o Império Inca usado para conter suprimentos, servir de alojamento de pessoal itinerante do Estado ou como depósito para registros contábeis baseados em quipus. Durante o gamonalismo eles foram tirados da comunidade e usados pessoalmente pelo Gamonales e Latifundiários como armazéns e lojas locais onde os trabalhadores foram forçados a trocar os créditos de seus futuros salários por bens.

31 Pensamiento Gonzalo ou Pensamento Gonzalo, são as adaptações de Abimael Guzman do Pensamento de Mao Zedong para a realidade peruana com supostas generalizações globais. A guerrilha conduzida pelo PCP, embora suportado pelo PCP e pelas massas locais e com base em uma linha de massas populares muitas vezes caiu no erro do ultra esquerdismo, pois via o revisionismo como o principal problema a ser enfrentado. Sobre o assunto ver IBARRA, Eduardo. El pez fuera del agua: crítica al ultraizquierdismo gonzaliano. Lima: J. Gutemberg, 2010.

32 Os Guaranis são uma das maiores etnias indígenas da América Latina. Sua população está espalhada pela Bolívia, Paraguai, Argentina, Uruguai e Brasil. Sua população brasileira é hoje de cerca de 40.000 indivíduos que cobrem as regiões sul e centro-oeste do Brasil. O Kaiowas, denominação exonímica do paĩ-tavyterã são um subgrupo da família guaranítica endógeno do Brasil. 33 O Ayllu, um clã familiar, é o tipo tradicional da comunidade andina, especialmente entre os povos Quéchua e Aymara.

34 O Nande Reko, que pode ser compreendido como "garantia para nosso caminho", é a forma pela qual a comunidade tribal se organiza em relação à vida material e espiritual.

35 Entendemos o Pensamento Mao Zedong (毛泽东思想)como a variedade do marxismo-leninismo desenvolvida pelo presidente Mao a fim de realizar uma revolução na sociedade agrícola, pré-industrial, semi feudal chinesa. Em oposição, o maoísmo deve ser entendido como os desenvolvimentos do chamado Pensamento Mao Zedong, a partir do salto qualitativo de seus aportes universais transportado localmente por marxistas e revolucionários posteriores que adaptaram criativamente o Pensamento Mao Zedong às suas próprias realidades. É o caso do PCP e de seu presidente Abimael Guzman.

36 Certamente não queremos que o socialismo na América seja uma cópia em papel carbono. Deve ser uma criação heroica. Temos que dar vida, com nossa própria realidade, em nossa própria língua, ao socialismo indo-americano. Aqui está uma missão digna de uma nova geração. Tradução nossa.

Recebido em: 28 nov. 2021

Aprovado em: 14 dez. 2021 